\title{
The fish assemblage of the Mondego estuary: composition, structure and trends over the past two decades
}

\author{
Ricardo Leitão $\cdot$ F. Martinho $\cdot$ H. N. Cabral • \\ J. M. Neto $\cdot$ I. Jorge $\cdot$ M. A. Pardal
}

(C) Springer Science+Business Media B.V. 2007

\begin{abstract}
The fish assemblage of the Mondego estuary was studied from June 2003 to May 2004. Five areas with different environmental conditions were sampled monthly, using a $2 \mathrm{~m}$ beam trawl ( $5 \mathrm{~mm}$ mesh size at the cod end). To complement information, sampling was also performed, seasonally, using a $7 \mathrm{~m}$ otter trawl with a $10 \mathrm{~mm}$ mesh size. Thirty-two species were identified. Dicentrarchus labrax, Pomatoschistus microps, Pomatoschistus minutus, Solea solea, Platichthys flesus and Diplodus vulgaris were the most abundant species. Marine juvenile migrants had the highest number of species, thirteen,
\end{abstract}

Guest editors: M. J. Costa, H. Cabral \& J. L. Costa Towards an integrated knowledge and management of estuarine systems

R. Leitão $(\bowtie) \cdot$ F. Martinho · J. M. Neto ·

M. A. Pardal

Institute of Marine Research (IMAR), Department of

Zoology, University of Coimbra, 3004-517 Coimbra,

Portugal

e-mail: ricvl@ci.uc.pt

H. N. Cabral

Instituto de Oceanografia, Faculdade de Ciências da

Universidade de Lisboa, Campo Grande, 1749-016

Lisboa, Portugal

\section{Jorge}

Instituto de Investigação das Pescas e do Mar CRIPCENTRO, Canal das Pirâmides, 3810 Aveiro, Portugal followed by estuarine residents with eight species. Marine species that use the estuary as nursery grounds were the most abundant in terms of density and biomass. In spring and summer, juveniles occur in the upper, oligohaline areas, but afterwards, in autumn and winter, they tend to disperse to the middle and lower areas, with higher marine influence. Comparing the results obtained in this study with those reported in the early 1990's, a marked decrease in species richness can be noticed, which is probably due to anthropogenic factors, namely an increase in depth of the main channel and intense euthrophication processes in the middle and upper areas.

Keywords Fish assemblage $\cdot$ Ecological guilds $\cdot$ Nursery $\cdot$ Species richness · Anthropogenic impacts · Eutrophication

\section{Introduction}

Estuaries have long been regarded as important sites for fish, both as nursery and overwintering grounds, migration routes and areas which naturally support large numbers of fish (Haedrich, 1983). This is related to high productivity levels, associated with increased availability of nutrients and abundance of primary producers, reduced incidents of piscivorous predators (McLusky, 1989) as well as high turbidity and sheltered areas. 
The classification of species into ecotrophic guilds is a strong tool to assess the structure of the fish communities. In 1995, Elliott \& Dewailly defined what may be termed a typical European (Atlantic seaboard) estuarine fish assemblage based on ecological guilds: a majority of taxa belonging to estuarine resident, marine adventitious or marine juveniles (each group, 25\%); a small number of marine seasonal migrants and diadromous taxa (each 10\%), and few (5\%) freshwater adventitious taxa. In Portugal, estuarine fish assemblages are well documented (e.g. Gordo \& Cabral, 2001; Costa et al., 2002; Jorge et al., 2002, among others) and, with few exceptions, follow this typical structure.

The Mondego estuary, located in the western coast of Portugal, has been historically impacted by human activities. Illegal fishing gear and nets of high efficiency and bycatch (such as fyke nets for glass-eel) have been continuously used in the Mondego estuary. In addition, from January to April, sea lamprey and shad are legally but still intensively fished using trammel and fyke nets, often below legal size and with large bycatch of other species.

Other sources of human pressure arrive from the regular dredging activities, in order to maintain shipping routes to a mercantile harbour, urban sewage still discharged without treatment and finally the areas typically used for salt exploration are being transformed into fish farm units where seabass and gilthead seabream are the most important cultivated species (Jorge et al., 2002). Additionally, the lower Mondego river valley consists of 15,000 ha of farming fields which supply an excess of nutrients into estuarine waters (Pardal et al., 2000; Martins et al., 2001). Similar to many estuaries all over the world, eutrophication largely increased in the Mondego since the 1980s, as a result of excessive nutrient release into coastal waters. The most visible feature of eutrophication in the Mondego estuary is the occurrence of seasonal green macroalgae blooms (mainly of Enteromorpha spp.), which have been reported in the south branch for several years (Marques et al., 1997; Pardal et al., 2000; Martins et al., 2001). Eutrophication, as a response to nutrient enrichment, commonly causes a shift from rooted plant communities, like the seagrass
Zostera, towards free-floating (or partially freefloating) faster-growing macroalgae, like Enteromorpha or Ulva. In the Mondego estuary, seagrass beds declined rapidly throughout the 19801990 period, macroalgal blooms increased and there have been marked changes in macroinvertebrate assemblages, mainly a progressive impoverishment in species diversity (Marques et al., 1997; Lillebø et al., 1999; Pardal et al., 2000; Martins et al., 2001; Cardoso et al., 2004, 2005).

The available data for the Mondego estuary fish community refers to a study conducted in the years of 1988, 1991 and 1992 by Jorge et al. (2002). Surveys were conducted before the increase in channel depth of the northern branch that most likely resulted in a rise of salinity and changes in freshwater fish community. On the other hand, eutrophication in the south branch led to a decrease in Zostera noltii (Hornemann, 1832) area, possibly resulting in a reduction of species related to seagrass beds. Also, the presence of dams constitutes physical migration barriers, which are known to affect anadromous species (Costa et al., 2001).

Due to the marked changes in the last 15 years on both branches of the estuary due to human disturbance, the aim of this work was to study the structure of the fish assemblage in the Mondego estuary, in order to assess the effect of dredging activities and eutrophication based on a comparison of two distinct temporal fish community data sets.

\section{Materials and methods}

\section{Study site}

The Mondego estuary is a warm-temperate coastal system on the western coast of Portugal with a surface area of $3.4 \mathrm{~km}^{2}$. About $75 \%$ of the estuarine area is intertidal. The estuary consists of a northern branch and a southern branch, with distinct hydrologic characteristics. The northern part is regularly dredged to maintain a depth between 5 and $10 \mathrm{~m}$ at high tide. The southern part is shallow (2-4 $\mathrm{m}$ deep at high tide) and largely silted up in the upstream areas. As a consequence, freshwater flows largely through the 
northern branch and the water circulation in the southern branch is mainly dependent on tidal activity and on the small freshwater input of a tributary, the Pranto river, which is controlled by a sluice.

The southern branch, displays a gradient in eutrophication (Pardal et al., 2000; 2004; Cardoso et al., 2004), from an area where a macrophytes community ( $Z$. noltii) is present, up to a heavily eutrophicated zone, in the inner areas, where Enteromorpha spp. blooms are frequently observed. In the 1980s, Z. noltii beds occupied a broad area along the southern branch (15 ha) reaching the innermost parts of the estuary. By the mid-1990s, Z. noltii become restricted to a small patch $\left(200 \mathrm{~m}^{2}\right)$ located downstream (Cardoso et al., 2004). Recently, after the implementation of mitigation measures a slow recovery has been observed (Cardoso et al., 2005).

Fish sampling and data analysis

The fish assemblage of the Mondego estuary was studied monthly, between June 2003 and May 2004, using a $2 \mathrm{~m}$ beam trawl, equipped with a tickler chain and $5 \mathrm{~mm}$ stretched mesh size in the cod end. Sampling was carried out during the night, at low water during spring tides, at five stations (A, B, C, D and E) (Fig. 1). Beam trawl surveys consisted of three hauls of $5 \mathrm{~min}$, covering a minimum area of $500 \mathrm{~m}^{2}$, in each of the five sampling stations.
Additionally, three hauls using an otter trawl were conducted seasonally (each three months), each of 10-15 min duration, at stations A, D and E. Data based on this sampling gear was only used to test the sampling efficiency of beam trawl and was not taken into account to characterize the fish community. Simultaneously, temperature, salinity, $\mathrm{pH}$ and dissolved oxygen were measured at the surface and near the bottom. During each season, sediment samples were collected using a Van Veen grab, in order to determine granulometry and benthic macroinvertebrates biomass at each site ( $\mathrm{g}$ ash free dry weight $\mathrm{m}^{-2}$ ). In order to compare the efficiency of both sampling strategies, a MannWhitney test was applied to densities and biomass data of the fish species that were caught using both beam and otter trawl. To perform this test, only the coincident sampling stations and months were taken into account.

Analysis of the community structure was based on six ecological guilds based on life history styles (adapted from Elliott \& Dewailly, 1995): estuarine resident species (ER), marine adventitious species (MA), freshwater adventitious species (FW), diadromous species (DI), marine juvenile migrant (MJ) and species that use the Mondego estuary as a nursery area (NU). For the last category (NU), estuaries are preferential nursery areas, contrasting with $\mathrm{MJ}$, whose juveniles use these habitats opportunistically, being more abundant in adjoining coastal areas (CCA).
Fig. 1 Location of sampling stations in the Mondego estuary

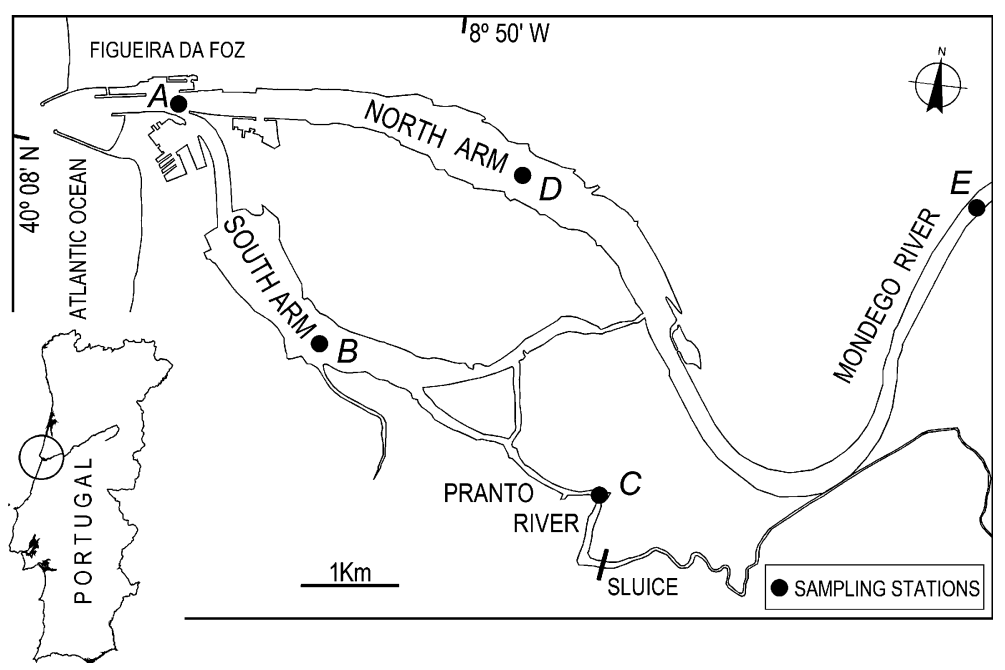


A canonical correspondence analysis was used to evaluate both spatial and temporal variation of the fish assemblage of the Mondego estuary in 2003-2004 surveys, using CANOCO 4.0 (Ter Braak, 1998). For each ecological guild, fish abundance (fish density as ind $1,000 \mathrm{~m}^{-2}$ ) was averaged by sampling area $(\mathrm{A}, \mathrm{B}, \mathrm{C}, \mathrm{D}$ and $\mathrm{E})$ and season (summer, autumn, winter and spring). The abundance of fish of the different ecological guilds was analyzed using a Kruskal-Wallis test and subsequent a posteriori tests (Zar, 1996).

Data on the Mondego fish assemblage based on samples taken in 1988, 1991 and 1992 were obtained from Jorge et al. (2002). Sampling was conducted monthly using a beach seine with a $7 \mathrm{~m}$ sac and $8 \mathrm{~mm}$ stretched mesh size in the cod end. Fishing was carried out during the day, at low water of spring tides, in three stations $(\mathrm{A}, \mathrm{C}$, and D). Available environmental data consisted of surface temperature and salinity. Only fish species and biomass data were available from this previous study. To compare the structure of both study periods, absolute biomass values were converted to percent composition, reducing the variability resulting from methodological differences while still retaining the relative abundance of individual taxa within each individual site's dataset (Mathieson et al., 2000). When comparing both study periods only the matching sampling stations were considered.

\section{Results}

Environmental characteristics of the sampling areas

The Mondego estuary shows a typical estuarine gradient, with depth, dissolved oxygen and salinity increasing downstream and reaching the highest values in station A, near the mouth (Table 1). Stations D and E, in the northern branch, registered a higher proportion of medium and coarse sand compared to the rest of the sampling

Table 1 Mean values (SD) of salinity, water temperature, dissolved oxygen, pH, percentage of silt, mud, fine sand, medium sand and large sand in the sediment, depth, benthic invertebrates biomass and algal cover biomass per sampling station

\begin{tabular}{|c|c|c|c|c|c|}
\hline & \multicolumn{5}{|c|}{ Sampling station } \\
\hline & A & $\mathrm{B}$ & $\mathrm{C}$ & $\mathrm{D}$ & $\mathrm{E}$ \\
\hline Salinity (ppm) & $\begin{array}{l}30.3 \\
(3.4)\end{array}$ & $\begin{array}{l}28.3 \\
(4.3)\end{array}$ & $\begin{array}{l}22.7 \\
(4.4)\end{array}$ & $\begin{array}{l}20.1 \\
(6.6)\end{array}$ & $\begin{array}{l}1.2 \\
(1.7)\end{array}$ \\
\hline Temperature $\left({ }^{\circ} \mathrm{C}\right)$ & $\begin{array}{l}15.6 \\
(2.7)\end{array}$ & $\begin{array}{l}17.2 \\
(3.1)\end{array}$ & $\begin{array}{l}18.0 \\
(5.3)\end{array}$ & $\begin{array}{l}16.8 \\
(3.6)\end{array}$ & $\begin{array}{l}17.2 \\
(5.4)\end{array}$ \\
\hline $\mathrm{O}_{2}(\%)$ & $\begin{array}{l}102.1 \\
(7.8)\end{array}$ & $\begin{array}{l}95.9 \\
(6.1)\end{array}$ & $\begin{array}{l}85.3 \\
(8.4)\end{array}$ & $\begin{array}{l}93.3 \\
(7.2)\end{array}$ & $\begin{array}{l}85.1 \\
(14.6)\end{array}$ \\
\hline $\mathrm{pH}$ & $\begin{array}{l}8.2 \\
(0.1)\end{array}$ & $\begin{array}{l}8.1 \\
(0.2)\end{array}$ & $\begin{array}{l}7.8 \\
(0.2)\end{array}$ & $\begin{array}{l}8.1 \\
(0.1)\end{array}$ & $\begin{array}{l}7.9 \\
(0.4)\end{array}$ \\
\hline$\%$ Silt & $\begin{array}{l}7.7 \\
(11.4)\end{array}$ & $\begin{array}{l}2.2 \\
(2.1)\end{array}$ & $\begin{array}{l}9.2 \\
(7.8)\end{array}$ & $\begin{array}{l}0.0 \\
(0.0)\end{array}$ & $\begin{array}{l}0.2 \\
(0.1)\end{array}$ \\
\hline$\%$ Mud & $\begin{array}{l}2.3 \\
(3.4)\end{array}$ & $\begin{array}{l}0.7 \\
(0.7)\end{array}$ & $\begin{array}{l}2.1 \\
(1.4)\end{array}$ & $\begin{array}{l}0.0 \\
(0.0)\end{array}$ & $\begin{array}{l}0.1 \\
(0.1)\end{array}$ \\
\hline$\%$ Fine sand & $\begin{array}{l}43.6 \\
(13.1)\end{array}$ & $\begin{array}{l}36.3 \\
(10.0)\end{array}$ & $\begin{array}{l}38.8 \\
(1.1)\end{array}$ & $\begin{array}{l}2.0 \\
(1.6)\end{array}$ & $\begin{array}{l}1.3 \\
(0.2)\end{array}$ \\
\hline$\%$ Medium sand & $\begin{array}{l}28.6 \\
(13.3)\end{array}$ & $\begin{array}{l}30.0 \\
(10.1)\end{array}$ & $\begin{array}{l}24.6 \\
(11.5)\end{array}$ & $\begin{array}{l}51.7 \\
(34.7)\end{array}$ & $\begin{array}{l}22.6 \\
(1.9)\end{array}$ \\
\hline$\%$ Coarse sand & $\begin{array}{l}16.5 \\
(21.4)\end{array}$ & $\begin{array}{l}30.5 \\
(19.1)\end{array}$ & $\begin{array}{l}24.1 \\
(12.5)\end{array}$ & $\begin{array}{l}45.9 \\
(36.5)\end{array}$ & $\begin{array}{l}75.5 \\
(1.5)\end{array}$ \\
\hline Depth (high tide) (m) & $\begin{array}{l}8.7 \\
(1.2)\end{array}$ & $\begin{array}{l}2.3 \\
(0.4)\end{array}$ & $\begin{array}{l}2.4 \\
(1.0)\end{array}$ & $\begin{array}{l}5.5 \\
(0.5)\end{array}$ & $\begin{array}{l}4.5 \\
(0.3)\end{array}$ \\
\hline Benthos biomass $\left(\mathrm{g} \mathrm{m}^{-2}\right)$ & $\begin{array}{l}3.6 \\
(5.3)\end{array}$ & $\begin{array}{l}0.4 \\
(0.2)\end{array}$ & $\begin{array}{l}1.2 \\
(1.2)\end{array}$ & $\begin{array}{l}0.0 \\
(0.0)\end{array}$ & $\begin{array}{l}3.8 \\
(4.6)\end{array}$ \\
\hline Algae biomass $\left(\mathrm{g} \mathrm{m}^{-2}\right)$ & $\begin{array}{l}0.5 \\
(0.5)\end{array}$ & $\begin{array}{l}0.9 \\
(2.3)\end{array}$ & $\begin{array}{l}2.9 \\
(3.6)\end{array}$ & $\begin{array}{l}0.0 \\
(0.0)\end{array}$ & $\begin{array}{l}0.0 \\
(0.0)\end{array}$ \\
\hline
\end{tabular}


areas where the sediment was mainly composed of fine sand and silt. Turbidity and algae biomass were highest at station $\mathrm{C}$, while station $\mathrm{E}$ presented the greatest benthic prey availability.

Species composition and ecological guilds

A total of 6371 individuals belonging to 22 families and 34 species were collected with beam trawl in the 2003-2004 surveys (Table 2). The fish assemblage of the Mondego estuary in the present study was dominated by Dicentrarchus labrax (Linnaeus, 1758), Pomatoschistus microps (Krøyer, 1838), Pomatoschistus minutus (Pallas, 1770), Diplodus vulgaris (Geoffroy Saint-Hilaire, 1817), Platichthys flesus (Linnaeus, 1758) and Solea solea (Linnaeus, 1758), corresponding to $91 \%$ of the total individuals caught. Concerning biomass, D. labrax, S. solea, P. flesus, Anguilla anguilla (Linnaeus, 1758), D. vulgaris and Barbus bocagei (Steindachner, 1864), accounted for $85 \%$ of the total.

Regarding the ecological guilds, also in 200304 surveys, the MJ were the dominant group with $32 \%$ of total number of species. Nursery (NU) group was the most abundant group, with $60 \%$ of the total number of individuals and $65 \%$ of the total biomass. Marine adventitious (MA) and estuarine residents (ER) groups represented 23\% and $20 \%$, respectively, of the number of species. Only three freshwater adventitious (FW) and two catadromous (DI) species were found (Table 2). All species caught by otter trawl (22) were also collected by the beam trawl surveys (34) (Table 2). No significant differences were found in densities $(U=244.0, \quad P>0.05)$ or biomass ( $U=201.5, P>0.05)$ of fish caught by the two methods.

\section{Spatial and temporal patterns}

In the summer, sampling station $\mathrm{C}$ registered the highest fish densities and station A during spring presented the highest species number (19). The first axis of the CCA performed using ecological guilds data according to sampling areas and seasons accounted for $50 \%$ of the total variance and $65 \%$ of the variance due to ecological groupsenvironment relationships. Second axis accounted for 14 and 18\%, respectively (Fig. 2). Among the environmental variables considered, dissolved oxygen, depth and benthos were the most influent ones, while fine sand had the weaker influence. Salinity, dissolved oxygen and depth were positively correlated, following a typical estuarine gradient, and were negatively correlated with temperature.

Significant differences in abundance were observed between all sampling stations for all ecological guilds with the exception of the freshwater adventitious group $(H=5.41, P>0.05)$. This revealed a spatial pattern with some fish occupying the upstream areas of the estuary and other being more abundant in sampling stations near the sea (a posteriori tests, $P<0.05$ ). Concerning the seasonal pattern, only the estuarine residents and MJ groups presented differences between seasons $(H=9.33, \quad P<0.05$ and $H=10.77, P<0.05$, respectively). In fact, and according to the CCA ordination diagram, two major groups were found: a) freshwater adventitious, nursery and catadromous species, associated with stations $\mathrm{C}$ and $\mathrm{E}$ in the upstream and less saline areas, and b) marine adventitious, MJs and estuarine residents, related to stations A, B and $\mathrm{D}$ (the downstream areas), with higher marine influence. The nursery group was closely related to stations $\mathrm{C}$ in spring, summer and autumn and $\mathrm{E}$ in summer and autumn. These stations were characterized by high algae biomass, elevated temperatures and a lower salinity.

Trends over the last two decades

Comparing data collected in both surveys we can see that average and maximum salinity in 20032004 was higher than in 1988, 1991 and 1992 while average temperature remained constant. Nevertheless, precipitation was slightly higher in 20032004 (Fig. 3). In the 1988-1992 surveys, a total of 62 species (27 families) were identified. Engraulidae, Centrarchidae, Gasterosteidae, Carangidae, Labridae and Scombridae were absent in the 2003-2004 samples (Table 2). In the baseline study (1988-1992), Liza ramada (Risso, 1810), D. labrax, Chelon labrosus (Risso, 1827), Liza aurata (Risso, 1810), Atherina spp. and Engraulis encrasicolus (Linnaeus, 1758) were the dominant 


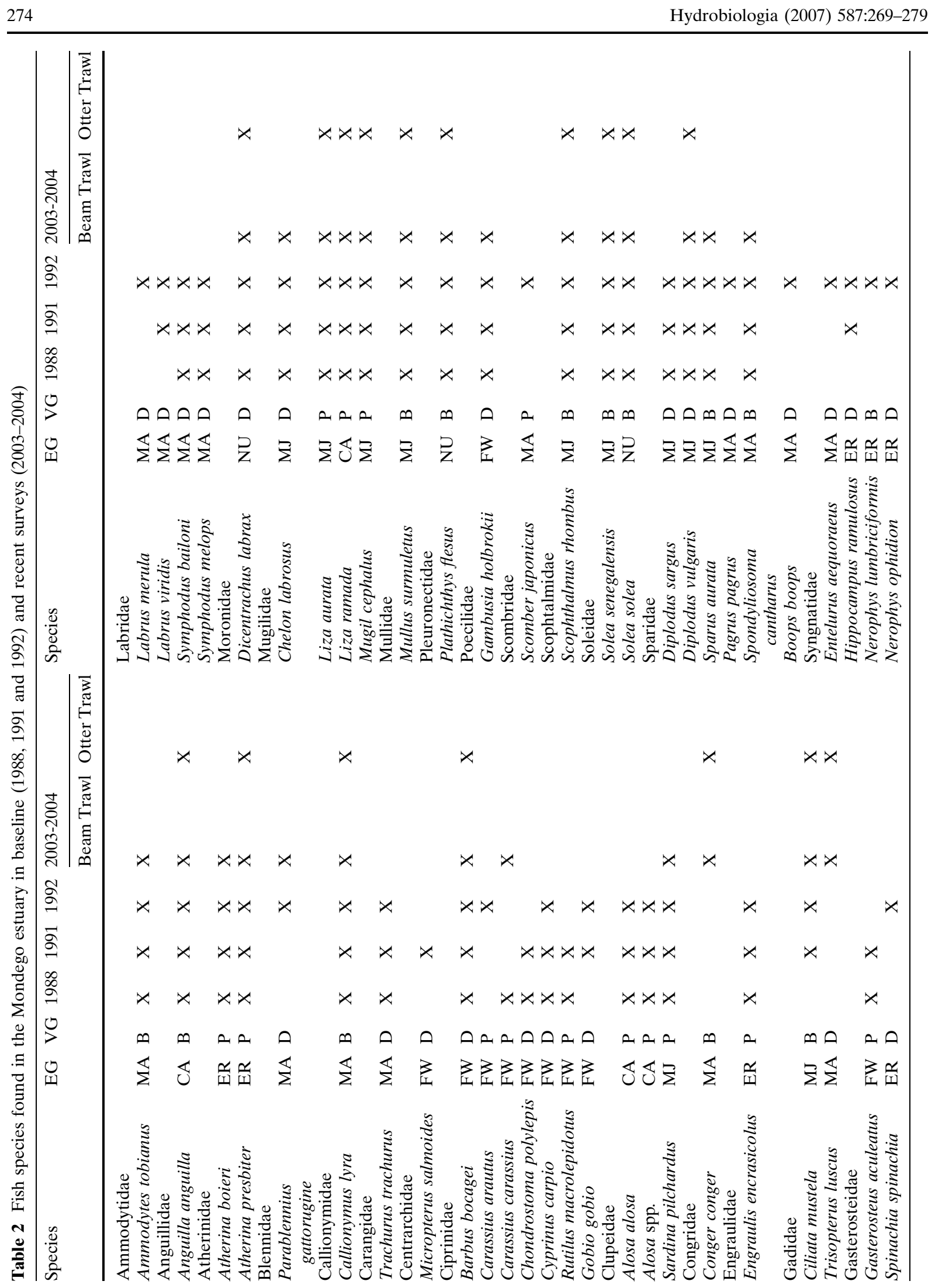

Springer 

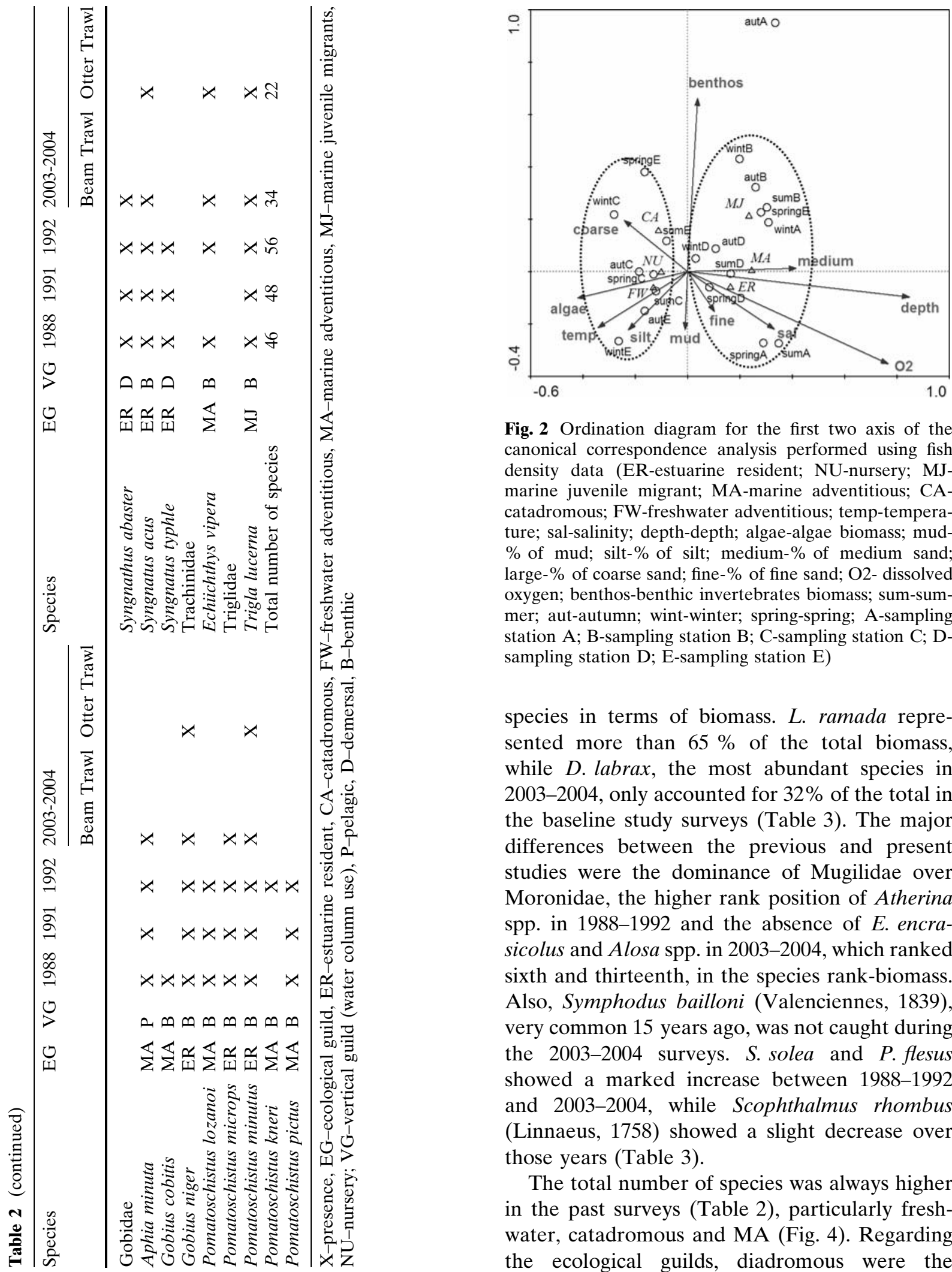

Fig. 2 Ordination diagram for the first two axis of the canonical correspondence analysis performed using fish density data (ER-estuarine resident; NU-nursery; MJmarine juvenile migrant; MA-marine adventitious; CAcatadromous; FW-freshwater adventitious; temp-temperature; sal-salinity; depth-depth; algae-algae biomass; mud$\%$ of mud; silt- $\%$ of silt; medium- $\%$ of medium sand; large- $\%$ of coarse sand; fine- $\%$ of fine sand; O2- dissolved oxygen; benthos-benthic invertebrates biomass; sum-summer; aut-autumn; wint-winter; spring-spring; A-sampling station A; B-sampling station B; C-sampling station C; Dsampling station D; E-sampling station E)

species in terms of biomass. L. ramada represented more than $65 \%$ of the total biomass, while D. labrax, the most abundant species in $2003-2004$, only accounted for $32 \%$ of the total in the baseline study surveys (Table 3 ). The major differences between the previous and present studies were the dominance of Mugilidae over Moronidae, the higher rank position of Atherina spp. in 1988-1992 and the absence of E. encrasicolus and Alosa spp. in 2003-2004, which ranked sixth and thirteenth, in the species rank-biomass. Also, Symphodus bailloni (Valenciennes, 1839), very common 15 years ago, was not caught during the 2003-2004 surveys. S. solea and P. flesus showed a marked increase between 1988-1992 and 2003-2004, while Scophthalmus rhombus (Linnaeus, 1758) showed a slight decrease over those years (Table 3).

The total number of species was always higher in the past surveys (Table 2), particularly freshwater, catadromous and MA (Fig. 4). Regarding the ecological guilds, diadromous were the 

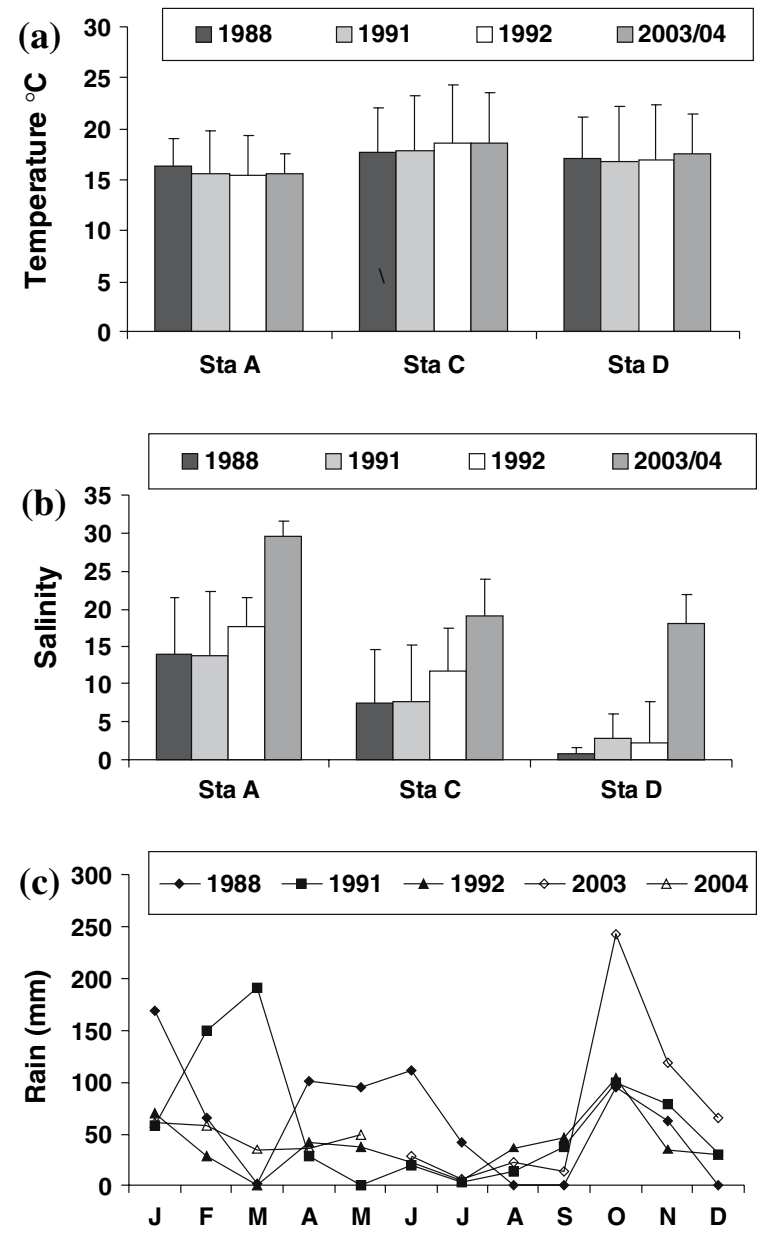

Fig. 3 Mean water temperature (a) and salinity (b) measured at the surface in stations A, C and D, in 1988, 1991, 1992 and 2003-2004; and monthly rain fall values in 1988, 1991, 1992, 2003 and 2004 (c)

dominant group in biomass in 1988, 1991 and 1992, mainly due to L. ramada, while in 20032004 the nursery group had the higher biomass values. The proportion of the other groups didn't change much over the years (Fig. 4).

\section{Discussion}

Spatial and temporal pattern in fish assemblage

In 2003-2004, species numbers according to ecological guild did not differ considerably from what Elliot \& Dewailly (1995) found for 17 European estuaries, being D. labrax, S. solea and P. flesus (species that use the Mondego estuary as nursery grounds) among the most abundant species.

The Mondego estuary fish assemblage is influenced by a longitudinal environmental gradient. Marine adventitious and marine juvenile species were associated with higher salinity and deeper areas and freshwater and catadromous species occupied areas with high freshwater input, indicating the spatial gradient as the main structuring factor of the fish community. However, and as reported for other estuarine systems, community structure is probably a result of a particular combination of several environmental factors, which renders the assessment of their individual importance difficult (Gordo \& Cabral, 2001).

While the movements of estuarine residents were not closely related to environmental variables, species from the nursery guild presented marked seasonal patterns of abundance. A summer and autumn abundance peak was observed, particularly for the juveniles, in stations $\mathrm{C}$ and $\mathrm{E}$. In winter and early spring, a downstream dispersion occurred, with nursery species being found in stations D and A, closer to the sea. This behavior was also referenced in other European estuarine systems (Aprahamian \& Barr, 1985; Jennings et al., 1991).

Trends-pollution and anthropogenic effects

The differences in the ichthyofaunal composition between the two study periods (1988-1992 and 2003-2004) are so pronounced that different sampling methods alone cannot be invoked to explain the observed trends. Nevertheless, in the 2003-2004 surveys, density and biomass estimates of L. ramada (a DI) and the other Mugilidae (marine migrant species) were possibly underestimated, which resulted in a higher frequency of nursery species biomass in 2003-2004. However, no differences between the two study periods, concerning nursery species, were registered. Atherina spp., another pelagic species, had also different rank positions. This could be attributed to the fact that beam trawl sampling provides a good indication of demersal and benthic fish communities (Hemingway \& Elliott, 2002) but may underestimate pelagic species (Thiel et al., 2003). On the other hand, beach seine virtually covers the entire water column. 
Table 3 Most abundant fish taxa ranked by biomass (\%) in 1988, 1991, 1992 and 2003-2004

\begin{tabular}{|c|c|c|c|c|c|c|c|c|}
\hline \multirow[t]{2}{*}{ Rank } & \multicolumn{2}{|l|}{1988} & \multicolumn{2}{|l|}{1991} & \multicolumn{2}{|l|}{1992} & \multicolumn{2}{|l|}{ 2003-2004 } \\
\hline & Species & Biomass & Species & Biomass & Species & Biomass & Species & Biomass \\
\hline 1 & L. ramada & 67.21 & L. ramada & 70.77 & L. ramada & 80.01 & D. labrax & 35.07 \\
\hline 2 & L. aurata & 8.89 & S. pilchardus & 8.92 & D. labrax & 5.81 & S. solea & 16.43 \\
\hline 3 & D. labrax & 8.26 & D. labrax & 4.93 & C. labrosus & 3.64 & P. flesus & 11.96 \\
\hline 4 & C. labrosus & 4.24 & C. labrosus & 4.03 & E. encrasicolus & 2.14 & A. anguilla & 10.72 \\
\hline 5 & S. aurata & 2.27 & L. aurata & 2.85 & L. aurata & 1.40 & D. vulgaris & 6.57 \\
\hline 6 & S. rhombus & 2.12 & D. vulgaris & 2.37 & Atherina spp. & 1.17 & L. ramada & 4.74 \\
\hline 7 & Atherina spp. & 2.06 & Alosa spp. & 1.47 & Alosa spp. & 0.87 & B. bocagei & 2.90 \\
\hline 8 & M. cephalus & 1.02 & Atherinidae & 0.95 & D. vulgaris & 0.59 & S. senegalensis & 1.80 \\
\hline 9 & E. encrasicolus & 0.86 & E. encrasicolus & 0.80 & S. rhombus & 0.48 & C. labrosus & 1.50 \\
\hline 10 & A. anguilla & 0.65 & S. rhombus & 0.67 & M. cephalus & 0.43 & S. rhombus & 1.33 \\
\hline 11 & T. lucerna & 0.53 & T. lucerna & 0.37 & S. pilchardus & 0.42 & T. lucerna & 1.24 \\
\hline 12 & D. vulgaris & 0.38 & M. cephalus & 0.35 & S. bailoni & 0.39 & P. minutus & 1.19 \\
\hline 13 & Alosa spp. & 0.27 & A. anguilla & 0.32 & T. lucerna & 0.39 & L. aurata & 0.91 \\
\hline 14 & G. niger & 0.22 & S. aurata & 0.15 & B. belone & 0.36 & S. aurata & 0.72 \\
\hline 15 & P. flesus & 0.18 & M. salmoides & 0.13 & A. anguilla & 0.26 & P. microps & 0.66 \\
\hline 16 & C. carpio & 0.18 & A. tobianus & 0.12 & B. bocagei & 0.23 & C. conger & 0.48 \\
\hline 17 & S. solea & 0.13 & B. bocagei & 0.11 & G. niger & 0.21 & Atherina spp. & 0.37 \\
\hline 18 & P. minutus & 0.14 & G. niger & 0.10 & C. lyra & 0.20 & $C$ mustela & 0.33 \\
\hline 19 & A. tobianus & 0.10 & C. carpio & 0.09 & C. carpio & 0.14 & G. niger & 0.21 \\
\hline 20 & M. surmuletus & 0.09 & B. belone & 0.09 & E. vipera & 0.13 & M.surmuletus & 0.20 \\
\hline
\end{tabular}
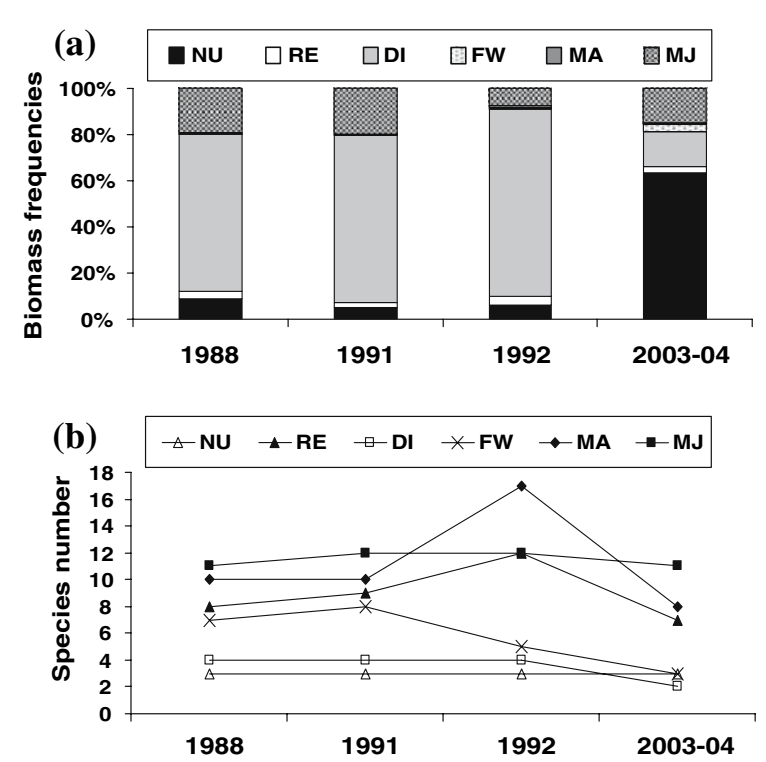

Fig. 4 Fish biomass (\%) (a) and species numbers (b) per ecological guild in 1988, 1991, 1992 and 2003-2004 (ERestuarine resident, CA-catadromous, FW-freshwater adventitious, MA-marine adventitious, MJ-marine juvenile migrants, NU-nursery)

Otter trawl, gifted with a wider area for catching, is more appropriate for capturing larger fish (Hemingway \& Elliott, 2002). Even though the fact that no new species were captured in otter trawl surveys could be used as an indicator of the efficiency of beam trawl sampling, particularly in a shallow estuary such as the Mondego estuary.

The conversion of absolute biomass values to percent composition, during data treatment, was a way of reducing the variability resulting from methodological differences and still retaining the relative abundance of individual taxa within each individual site's dataset (Mathieson et al., 2000).

The lower fish diversity in the 2003-2004 surveys could be in part a result of an impoverishment of the environmental quality of the Mondego estuary in the last fifteen years. One of the main differences between the previous and present study is the low number of FW in 20032004 surveys, with only three species found: B. bocagei, Carassius carassius (Linnaeus, 1758) and Gambusia holbrooki (Girard, 1859), while in the 1988-1992 study ten species were registered. This major difference could be attributed to salinity changes. The average surface water salinity in 2003-2004 in the sampling stations common to both studies was always higher compared to baseline values, although it was a rainy year (Fig. 3). This situation was more 
significant in station D (the north branch), where freshwater species were previously more abundant. This situation could be a result of the dredging activities near the mouth, in order to deepen the shipping channel. The increase of depth induces an increase of the tidal exchange: the tidal range increases, the tide incursion progresses to upstream, the salinity front and the turbidity maximum zone migrate to the upper reaches and, the current speed increases leading to the filling of shallow areas and erosion of banks (Marchand et al., 2002).

In the Mondego estuary (Portugal), eutrophication has triggered serious biological changes, which led to an overall increase in primary production and to a progressive replacement of seagrass $Z$. noltii beds by coarser sediments and opportunistic macroalgae (Cardoso et al., 2004). The lower number of species observed in the present study could be also a result of this process. According to Raffaelli et al. (1998), in shallow sublittoral or intertidal habitats, biomass accumulations of attached or drift macroalgae reduce survival of invertebrate recruits, and reduced abundance of invertebrate prey for fishes and shore birds. Many authors (Reise, 1983; Hull, 1987; Raffaelli et al., 1989; Pihl et al., 1994; Cardoso et al., 2004; Pardal et al., 2004) already described these changes in invertebrate and fish assemblages. In the Clyde estuary (United Kingdom), reductions in organic pollution led to the return of missing fish species (Warfe et al., 1984). Henderson \& Hamilton (1986) related the continuing improvements in water quality and recovery of the invertebrate benthos, with positive changes in the fish populations in Clyde estuary. Indeed, Hippocampus hippocampus (Linnaeus, 1758), Symphodus melops (Linnaeus, 1758), S. bailloni and Labrus spp., which are species that live in association with seagrass beds (Costa et al., 2002), were present in the 1988-1992 surveys and absent in 2003-2004.

Alosa spp., highly abundant in the past study, was also missing in 2003-2004. It is known that river flow regulation by dams causing unnatural seasonal flow conditions has important effects on the diadromous fish species, namely shad (Alosa spp.) and lamprey (Petromyzon marinus Linnaeus, 1758) (Costa \& Cabral, 1999). There are evidences of shad reduction (Tagus estuary) or even complete disappearance (Thames estuary). By the end of the nineteenth century twaite shad (Alosa fallax (Lacepède, 1803)) was not found in the middle or upper reaches of the tidal Thames. This demise was probably linked to the increase of pollution levels and overfishing (Whitfield \& Elliott, 2002), a situation also observed in the Mondego estuary.

The slight decrease in biomass-species rank position of the $S$. rhombus and the increase in the abundance of $S$. solea and $P$. flesus could reflect some competition behavior between those species and/or different tolerances to habitat changes. These three species are flatfishes with similar ecological niches (individuals belonging to the second and third year class of those species concentrate in stations A and D) and differences in sampling methods will have no influence in their captures.

The disappearance of the anchovy, E. encrasicolus, an abundant species in the past (Jorge et al., 2002), remains without explanation. There are evidences of this situation in other Portuguese estuaries, namely the Tagus Estuary, where the anchovy has become extremely rare within the estuary but occur in the adjacent coastal area (Prista et al., 2003).

Overall, this work has provided evidence of changes in the structure of the Mondego estuary fish assemblage over the last fifteen years, which may be a result in a large extent, from dredging activities (mainly in the north branch) and, indirectly, from eutrophication process (mainly in the south branch). Nevertheless, an integrated monitoring plan is recommended to be extended in the future, in order to assess the success of the mitigation measures implemented since 1999 (Cardoso et al., 2004), and to evaluate interannual variation in fish assemblage and to try to distinguish anthropogenic pressures effects from natural induced changes.

\section{References}

Aprahamian, M. W. \& C. D. Barr, 1985. The growth, abundance and diet of 0-group sea bass, Dicentrarchus labrax, from the Severn Estuary. Journal of the Marine Biological Association of the United Kingdom 65: 19-180. 
Cardoso, P. G., A. Brandão, M. A. Pardal, D. Raffaelli \& J. C. Marques, 2005. The resilience of Hydrobia ulvae populations to anthropogenic and natural disturbances. Marine Ecology Progress Series 289: 211-219.

Cardoso, P. G., M. A. Pardal, A. I. Lillebø, S. M. Ferreira, D. Raffaeli \& J. C. Marques, 2004. Dynamic changes in seagrass assemblages under eutrophication and implications for recovery. Journal of Experimental Marine Biology and Ecology 302: 233-248.

Costa, M. J., P. R. Almeida, I. M. Domingos, J. L. Costa, M. J. Correia, M. L. Chaves \& C. M. Teixeira, 2001. Present status of the main shad's population in Portugal. Bulletin Français de la Pêche et de la Pisciculture 362: 1109-1116.

Costa, M. J. \& H. N. Cabral, 1999. Changes in the Tagus nursery function for commercial fish species: some perspectives for management. Aquatic Ecology 33: 287-292.

Costa, M. J., C. I. Santos \& H. N. Cabral, 2002. Comparative analysis of a temperate and tropical seagrass bed fish assemblages in two estuarine systems: the Mira estuary (Portugal) and the Mussulo lagoon (Angola). Cahiers de Biologie Marine 43: 73-81.

Elliott, M. \& F. Dewailly, 1995. The structure and components of European estuarine fish assemblages. Netherlands Journal of Aquatic Ecology 29: 397-417.

Gordo, L. S. \& H. N. Cabral, 2001. The fish assemblage structure of a hydrologically altered coastal lagoon: the Óbidos lagoon (Portugal). Hydrobiologia 459: 125-133.

Haedrich, R. L., 1983. Estuarine Fishes. In Ketchum, B. (ed.), Ecosystems of the World. 26 Estuaries and Enclosed Seas. Elsevier, Amsterdam, 183-207.

Hemingway, K. L. \& M. Elliott, 2002. Field Methods. In Elliott, M. \& K. Hemingway (eds), Fishes in Estuaries. Blackwell Science, Iowa.

Henderson, R. A. \& J. D. Hamilton, 1986. The status of fish populations in the Clyde estuary. Proceedings of the Royal Society of Edinburgh 90: 157-170.

Hull, S. C., 1987. Macroalgal mats and species abundance: a field experiment. Estuarine, Coastal and Shelf Science 25: 519-532.

Jennings, S., J. E. Lankaster, J. S. Ryland \& S. E. Shackley, 1991. The age structure and growth dynamics of young-of-the-year bass, Dicentrarchus labrax, populations. Journal of the Marine Biological Association of the United Kingdom 71: 799-810.

Jorge, I., C. C. Monteiro \& G. Lasserre, 2002. Fish Community of Mondego Estuary: Space-Temporal Organization. In Pardal, M. A., J. C. Marques \& M. A. Graça (eds), Aquatic Ecology of the Mondego River Basin. Global Importance of Local Experience. Imprensa da Universidade de Coimbra, Coimbra.

Lillebø, A. I., M. A. Pardal \& J. C. Marques, 1999. Population structure, dynamics and production of Hydrobia ulvae (Pennant) (Mollusca: Prosobranchia) along an eutrophication gradient in the Mondego estuary (Portugal). Acta Oecologica 20: 289-304.

Marchand, J., I. Codling, P. Drake, M. Elliott, L. Pihl \& J. Rebelo, 2002. Environmental Quality of Estuaries.
In Elliott, M. \& K. Hemingway (eds), Fishes in Estuaries. Blackwell Science, Iowa.

Marques, J. C., M. A. Pardal, S. N. Nielsen \& S. E. Jørgensen, 1997. Analysis of the properties of energy and biodiversity along an estuarine gradient of eutrophication. Ecological Modeling 102: 155-167.

Martins, I., M. A. Pardal, A. I. Lilleb $\varnothing$, M. R. Flindt \& J. C. Marques, 2001. Hydrodynamics as a major factor controlling the occurrence of green macroalgal blooms in a eutrophic estuary: a case study on the influence of precipitation and river management. Estuarine, Coastal and Shelf Science 52: 165-177.

Mathieson, S., A. Cattrijsse, M. J. Costa, P. Drake, M. Elliott, J. Gardner \& J. Marchand, 2000. Fish assemblages of European tidal marshes: a comparison based on species, families and functional guilds. Marine Ecology Progress Series 204: 225-242.

McLusky, D. S., 1989. The estuarine ecosystem. Blackie, Glasgow.

Pardal, M. A., P. G. Cardoso, J. P. Sousa, J. C. Marques \& D. Raffaelli, 2004. Assessing environmental quality: a novel approach. Marine Ecology Progress Series 267: $1-8$.

Pardal, M. A., J. C. Marques, I. Metelo, A. I. Lillebø \& M. R. Flindt, 2000. Impact of eutrophication on the life cycle, population dynamics and production of $\mathrm{Am}$ phitoe valida (Amphipoda) along an estuarine spatial gradient (Mondego estuary, Portugal). Marine Ecology Progress Series 196: 207-219.

Pihl, L., H. Wennhage \& S. Nilsson, 1994. Fish assemblage structure in relation to macrophyts and filamentous epiphytes in shallow non-tidal rocky and soft bottom habitats. Environmental Biology of Fishes 39: 271288.

Prista, N., R. P. Vasconcelos, M. J. Costa \& H. Cabral, 2003. The demersal fish assemblage of the coastal area adjacent to the Tagus estuary (Portugal): relationships with environmental conditions. Oceanologica Acta 26: 525-536.

Raffaelli, D. G., S. Hull \& H. Milne, 1989. Long-term changes in nutrients, weed mats and shorebirds in an estuarine system. Cahiers de Biologie Marine 30: 259270.

Raffaelli, D. G., J. A. Raven \& L. J. Poole, 1998. Ecological impacts of green macroalgal blooms. Oceanography Marine Biology: An Annual Review 36: 97-125.

Ter Braak, C. J. F. \& P. Smilauer, 1998. CANOCO Reference Manual and User's Guide to Canoco for Windows: software for Canonical Community Ordination (version 4). Microcomputer Power, Ithaca, New York.

Wharfe, J. R., S. R. Wilson \& R. A. Dines, 1984. Observations on the fish populations of an East coast estuary. Marine Pollution Bulletin 15: 133-136.

Whitfield, A. K \& M. Elliott, 2002. Fishes as indicators of environmental and ecological changes within estuaries: a review of progress and some suggestions for the future. Journal of Fish Biology 61: 229-250.

Zar, J., 1996. Biostatistical Analysis. 3rd edn. Prentice Hall, Englewood Cliffs, New Jersey. 